\title{
Sector Wide Approach in Health: Policy Response and Framework in Zimbabwe
}

\author{
Hope Taderera (Corresponding author) Alois Madhekeni, and Gideon Zhou \\ Department of Political and Administrative Studies, \\ University of Zimbabwe, Harare, Zimbabwe
}

E-mail: htaderera@gmail.com, Tel: +263 774493522

Tafadzwa Chevo

Department of Sociology, University of Zimbabwe

Received: February 20, 2012 Accepted: April 10, 2012 DOI: 10.5296/jpag.v2i1.1570

\begin{abstract}
The discourse is on the Sector Wide Approach (SWAp) in health, a policy reform intervention by the World Health Organization, and focuses on Zimbabwe's response, and the subsequent health policy framework. A SWAp is a government led partnership with donor agencies and the civil society, in the formulation, implementation, monitoring and evaluation of the health policy. The rationale is to systematically build the capacity of health delivery systems and structures, for the realization health policy objectives through effective and efficient utilization of collaboratively mobilized resources for the realization of sustainable development in health. Zimbabwe has responded to SWAps by adopting the WHO Country Cooperation Strategy (2008-2013), being implemented through the National Health Strategy (2009-2013). A collaborative approach involving the state and civil society is being pursued. Within this arrangement, the Ministry of Health and Child Welfare is leading the strategic and operational function, at all levels of society, with the donor community, through the civil society playing a supportive role particularly in areas which include HIV/AIDS, tuberculosis, malaria, water and sanitation, and maternal health. Coordination is done through the National Planning Forum, made up of the health ministry and the voluntary sector, and the Health Development Partners Coordination Group, made up of donor agencies in health, in line with the Zimbabwe United Nations Development Assistance Framework and the Interagency Humanitarian Coordination Mechanism. It was concluded that a framework has been put in place through which the SWAp is being pursued, towards systematic capacity building of Zimbabwe's health sector.
\end{abstract}

Keywords: Sector Wide Approach in health, policy framework, Zimbabwe 


\section{Introduction}

In a number of low-income countries, governments and donors are departing from traditional ways of operating by embarking on a new approach to reforming the health sector. Known in other sections as the Sector Investment Program, this approach has recently been called the Sector-Wide Approach to Health Development (SWAp) (Cassels, 1997). The SWAp is based on a new type of partnership, led by the government, and involving a number of donor agencies and other groups in the civil society. The approach has changed the tools used to promote sector reforms and manage development assistance. It has however also raised new challenges in the implementation and coordination of the health policy, and provided new ways to deal with long-standing conflicts over priorities of values, technologies, and processes. The current discourse explains the SWAp, and its rationale in the health sector. It also explains the policy response and framework in Zimbabwe, to this emergent intervention that has come to characterise the majority of service delivery systems in Sub Saharan Africa, thus laying a foundation upon which future analysis and discourse may be pursued.

\section{Sector Wide Approach: Some conceptual issues}

A Sector Wide Approach (SWAp) is a sustained government-led partnership with donor agencies and the civil society in-which sector-wide interventions are applied to an expenditure framework and national implementation system for the health policy (Peters and Shiyan, 1998). Foster et at. (2000) describe it as all significant funding for the sector which supports a single sector policy and expenditure programme, under government leadership, adopting common approaches across the sector, and progressing towards relying on government procedures to disclose and account for all funds. Explicit health sector reforms are undertaken to meet sectoral and national development objectives. The approach has changed the dynamic between governments and donor agencies, requiring systemic changes in public policy-making and management by the government and donor agencies (Foster et al., 2000; Peters and Shiyan, 1998). There are persuasive arguments for supporting a SWAp as opposed to the traditional project approach.

Amongst these include increased health sector coordination, stronger national leadership and ownership, and strengthened countrywide management and delivery systems. These are variously claimed to reduce duplication, lower transaction costs, increase equity and sustainability, and improve aid effectiveness and health sector efficiency (Brown, 2000; 2002; Travis, 2004). Furthermore, the SWAp has become an integral part of poverty reduction strategies, and its ideology has enjoyed a growing acceptance from donor agencies and aid recipients in other parts of the world (Michaud and Murray, 1994). By design, SWAps are intended to reinforce national leadership, transparent decision making processes, and institutional capacity building. Many countries are enthusiastic about trying out SWAps, as governments see the opportunity to build capacity in the health sector. SWAps have been supported in Pakistan, Zambia, Mozambique, Ghana, Senegal, Bangladesh, and Sierra Leone. Officials in a number of other countries, including Cambodia, Eritrea, Ethiopia, Guinea Bissau, Kenya, Laos, Mali, Mauritania, Tanzania, Uganda, and others, have indicated varying degrees 
of intent in pursuing this approach (Dollar and Pritchett, 1998; Gilson et al., 1997; Peters and Shuyan, 1998). There is also considerable misunderstanding and justifiable scepticism about the approach.

It is not uncommon for a SWAp to be misconceived as a prescriptive lending instrument intended to push the agenda of an external agency, typically the World Bank (Cassels, 1997). Several international efforts have been made to clarify concepts and delineate working arrangements. The group of donors supporting the Special Program in Africa is closely monitoring the development of Sector Investment Programs in a number of sectors, including health. In early 1997, a meeting among over 20 donor agencies was held to come to a common understanding on the meaning of SWAps in the health sector, followed by another meeting with national officials to further develop the SWAp (Cassels, 1997; Dollar and Pritchett, 1998). Nevertheless, in order to understand the potential impact of this approach on population health, capacity is built around four key areas which have implications for public health. These four areas include country leadership and ownership, institutional and management capacity, flow of resources, and monitoring and evaluation.

\subsection{Leadership and ownership}

A SWAp explicitly mandates the ministry of health with the leadership. However, this role has been partly challenging owing to limited leadership capacity in some countries such as Rwanda, and poor relationship with the ministry of finance, as was the case in Mozambique (Peters and Shiyan, 1998). Other challenges emanate from the slow shift of ownership as that which was characteristic in Cambodia, change of senior management as was the case in Zambia, limited autonomy in securing additional funds by the ministry of health as was the case in United Republic of Tanzania, and low priority of cross-sectoral collaboration (Ibid).

\subsection{Institutional and management capacity}

Emphasis is also on building capacity so as to strengthen health sector management through the development or adaptation of management tools combined with strengthening of the implementation capacity (Addai, 2001). For example, under SWAps greater attention is given to health sector planning, financial management, and improved health information systems. SWAps also tend to emphasize strengthening district level management capability within existing decentralization policies (Ibid).

\subsection{Flow of resources}

Under a SWAp, recipient governments and donors only fund activities in the national health sector plan. Donor funds are pooled and earmarked for high priority activities, such as an essential health package (Peters and Shiyan, 1998). Importantly, pooled donor funding complements and supports government budgets giving a much needed boost to recurrent 
expenditures. Furthermore, donors are responsible for synchronizing their own planning, review and monitoring processes with government systems, and give long-term projections of aid pledges. These positive developments, however, are under threat in many SWAp countries, where global health initiatives are redefining modalities of aid delivery.

\subsection{Monitoring and evaluation}

Monitoring and evaluation of the health sector become institutionalized under a SWAp. The one voice of donors has strengthened their position to create conditions. The once or twice yearly joint review meetings are an important instrument providing an open forum to review of progress and performance of the health sector. These large meetings are complemented by more frequent meetings with key development partners. The success of these processes depends mainly on the people involved and their experience, expertise and sensitivity to developing partnerships (Ibid). Accurate and comprehensive monitoring programmes tailored to specific system contexts must be set up, preferably based on demographic surveillance systems.

Given the wide range of activities initiated or supported by a SWAp and the high level of support given by donors and recipient governments, the dearth of evidence on health impact is surprising. What is clear from some case studies is that there emerge patterns under which a SWAp can and will work, while other conditions are less favourable. It is also worth noting that sustained reform takes time given some challenges and the dilapidated state of the health sector in many of the countries where SWAps are in progress. It may take 5-10 years of sustained implementation before any sizeable impact on health outcomes can be demonstrated (Addai, 2001; Cassels, 1997).

\section{The main elements of the SWAp}

\subsection{The policy framework}

Nearly every country has some form of health policy that already exists. In low-income countries, much of the policy rhetoric is shaped by the Declaration of Alma Ata, which placed importance on equity in health care, and the central role of primary health care (WHO/UNICEF, 1978). However, the Alma Ata conference did not anticipate the severe economic constraints and declines in health budgets that followed, and many policies based on the Declaration did not adjust well to these circumstances. Despite considerable success in countries that have pursued such policies, most health systems in low-income countries are still characterized as under-funded and of poor quality. Common problems include a bias toward urban-based, publicly provided, tertiary curative care, little attention to maintenance and on-going operations, and bloated, poorly motivated, and inadequately trained and supervised work forces (Ibid). Much of the frustration over the disparity between policy expectations and performance has led to cynicism about more comprehensive approaches. Depending on their design, comprehensive approaches have been caricatured as either community based and ineffectual, or as centrally planned or un-implementable (Peters and 
Shiyan, 1998). This has created an environment where priority programs have continued to be pursued in isolation of each other, and policy-making itself has become devalued. The relative disappointment of past health policies may in part be due to the manner in which policies were formulated, the limited types of issues they addressed, and by the lack of tools to ensure their application.

Policy-making tended to be a one-off exercise, resulting in policy documents that did not identify allocation decisions or processes for dealing with future policy issues. By way of contrast, SWAps have concentrated on how policy choices are made, implemented and monitored on a regular basis (Addai, 2001; Cassels, 1997; Saltman, 1994). Policies developed under SWAps need to be explicit about resource allocation priorities as one means of translating statements of intent to action. Budgeting and review of financial records are intimately linked to policy review and planning in SWAps. As is increasingly common, the policy processes also have involved a great deal of consultation (Peters and Shiyan, 1998). In low-income countries undertaking SWAps, the content of health policy reforms has not concerned the introduction of market-oriented experiments and financing mechanisms that dominate European reforms and the academic literature (Saltman, 1994). Rather, policies are more likely to address basic systemic questions such as allocation priorities, the role of government, private, and not-for-profit sectors, and capacity-building in key support systems. They are also more likely to address questions such as organization of delivery systems, the content of services provided, the relationship of health delivery to health care users and beneficiaries, and the policy-making processes themselves. What the SWAp has demanded of new health policies is that they be far more explicit than their predecessors, and that they be formulated to address real choices for the sector. As a result, progress in implementation of health policies is also easy to monitor, and may provide a rationale for a financier to determine how much to contribute (Ibid).

\subsection{The expenditure framework}

In the SWAp, the public expenditure program is designed to reflect macro-economic policy and sector priorities and strategies in a transparent manner. They are also designed to reinforce the national budget process rather than to detail items to be funded as is done with traditional projects (Cassels, 1997; Walt et al., 1999). The expenditure frameworks generally use medium-term projections of resources available for the health sector from public, private, and donor sources. The overall expenditure framework is then translated into medium-term financing plans and short-term budgets. Ghana, Zambia, Senegal and Pakistan are good examples where this is happening (though in Pakistan, the scope of the program covers only the basic level of health system, as well as population, basic education, and rural water and sanitation). The fiscal efforts of government and donors are tracked against the budget, which is also the main tool for translating policy decisions about resources into reality (Peters and Shiyan, 1998). For example, a policy statement advocating greater support to primary health care would not succeed unless the budget actually demonstrated increased allocation to this level of services. 
In practice, SWAp partnerships have concerned themselves with allocation decisions made at the national level (or at the state level in larger countries) where the decisions are about the overall balance between capital and recurrent items, wage versus non-wage expenditures, regional variation, different levels of the system, and program preferences. Large investment decisions, such as those concerning major hospital construction and rehabilitation are also typically made at the central level. This is in contrast to micro-level decisions about efficiencies at the district level or individual facility, which are generally made by the unit involved, rather than with the involvement of partners. The issue of balancing resources between sectors is addressed through the SWAp. In the cases of Pakistan, Zambia, Mozambique, Senegal, Ghana and Sierra Leone (prior to the 1997 military overthrow of the civilian government), it has resulted in increasing resource flows to the health sector. All the countries that have undertaken a SWAp had suffered from very low and usually declining levels of public financing of the health sector. Prior to undertaking a SWAp, public expenditures on health ranged from $\$ 3$ per capita in Pakistan to $\$ 14$ per capita in Zambia, in each case comprising 2 per cent or less of gross domestic product (Ibid). The expenditure frameworks worked out in each country has increased both government and donor levels of financing the health sector over the medium term.

\subsection{The institutional framework}

One of the main technical innovations of the SWAp is the concentrated efforts on building and using national management systems to plan, monitor performance, and undertake the day-to-day business of purchasing and delivering goods and services (Cassels, 1997). The purpose is not merely to harmonize donor procedures in the name of efficiency, but to build capacity and instil appropriate incentives that would lead to sustainable health systems. In doing so, governments allow donors to take collective responsibility with them for achievements of the sector. The SWAps to date have been most successful in developing policy and plans for the health sector that are jointly agreed to by all financiers, and secondly in setting up systems to monitor performance. The greatest difficulty has been in developing and using national systems for procurement, accounting and auditing (Cassels, 1997; Conway, 2000). In all countries using a SWAp, a common plan has driven the preparation phases.

Open policy discussions have helped to facilitate agreement on the plans themselves. Some of the plans have been constructed as a comprehensive rationalization of strategies, projects and financing across the sector, particularly in Mozambique and Sierra Leone, and to a lesser degree in Senegal and Zambia (Peters and Shiyan, 1998). Other health plans, such as Ghana's Five Year Program of Work, place less emphasis on individual financiers and projects, and more on the plans and financing of cost centers responsible for implementing a budget, using all sources of financing, including private payments. In all the countries using a SWAp, there is considerable flexibility by developing and reviewing operational plans on a year-to-year basis, which tends to reinforce government planning and budgeting processes. All the plans developed under SWAps have been considered successful at this early stage, since the Ministry's hand has been strengthened in areas where it has clear authority, and all the participating agencies have gained a better understanding of the sector and how to operate 
within it. The plans have laid out clear linkages between policy, allocation of funds, and performance. The degree of confidence in financial management systems is an important factor in determining how donors and Ministries of Finance disburse funds. In all countries where a SWAp is being pursued, the initial step has been to strengthen the structure of public budgets (including government and donor funds) to better monitor spending patterns (Ibid). If an underlying assumption of the SWAp is that all funds used for the sector are to be used toward common purposes, then financing separate projects is less justified. However, the recognition that funds are fungible also means that funds will be used for recurrent costs, which is still a barrier for some agencies. The other barrier is that any use of a common account to pool donor funds would need to demonstrate probity and efficiency through proper cash management, accounting, reporting, and independent auditing (Dollar and Pritchett, 1998). Although many governments would prefer common funding because of the flexibility it offers, the use of a common account is thus relatively uncommon.

Zambia has a common basket account from donors to finance non-wage district level activities, which is managed by special procedures other than its government funds, and involves intensive donor scrutiny (Peters and Shiyan, 1998). Ghana utilizes a more comprehensive common account for donor funds than is used for any non-wage activities at any level. Ghana's common account has been built upon significant investments in financial management systems and supervision as part of the changing government financial management systems. Both countries still operate project accounts for individual donors, but are phasing them out, and increasingly using them to redirect funds on an annual basis, and report expenditures to the Ministry. In Pakistan, where there are fewer donors and much of the aid has flowed directly through government channels rather than other accounts, there is less need for a common account to pool funds. With these experiences, there is growing understanding and acceptance among donors on the type of accounting systems, reporting, and use of auditors needed to utilize country-based financial systems (Cassels, 1997; Peters and Shiyan, 1998). In none of the countries undertaking SWAps has procurement been entirely shifted over to government rather than donor systems. In most countries, the procurement procedures follow the rules of the source of the funds. Ghana has probably gone further than any of the other countries in this regard because it is using a common account, though ironically it does not yet have a national procurement code.

Ghana now has an agreed set of Government procurement and financial management procedures for the health sector, and is investing heavily in developing and auditing its procurement systems. The challenges to be overcome include not only the often limited technical capacity within countries and the opportunities for corruption, but the need for donors to account for their funds individually, and often to support business from their own country. Nonetheless, some agencies have been able to relax regulations regarding rules of origin, and Ghana has been able to negotiate decreasing amounts of tied aid from bilateral and regional financiers (Ibid). The design of appropriate monitoring systems has not been simple in countries undertaking SWAps.

One challenge is to reach a manageable number of indicators at the national level that can 
usefully indicate overall sector performance on a frequency that supports the types systems and decisions made on an ongoing basis, for example annual plans and budgets (Dollar and Pritchett, 1998; Travis et al., 2004; Michaud and Murray, 1994). The selection has been more a matter of negotiations in each country rather than adherence to a single set of indicators, an approach which has dominated many of the past international initiatives. There appears to be a consensus on a broad type of framework that is appropriate for a SWAp, particularly if there is to be a transparent link between funding and sector performance (Ibid). Cassels (1997) proposes that an appropriate national framework should include regular monitoring of individual cost centres, aggregate assessment of sectoral performance covering such domains as health outcomes in different groups, coverage, service quality, consumer satisfaction, and monitoring achievements in policy, financial management, and institutional development. In practice, the number of national indicators varies considerably. For example, there are nine national level indicators in Senegal, 20 in Ghana, 23 in Mozambique, and 40 in Sierra Leone (Peters and Shiyan, 1998).

\section{The rationale behind SWAps}

Over the last decade, critics have become increasingly vocal in opposing foreign assistance as wasteful or even counter-productive (Addai, 2001; Dollar and Pritchett, 1998; Travis et al., 2004). Whereas there are anecdotal cases where aid has supported regimes pursuing questionable economic and sectoral policies, and a common view that aid could be managed more efficiently, there is little systematic evidence that aid itself causes harmful policies to be pursued (Dollar and Pritchett, 1998). Regardless, the end of the Cold War has created a new environment for aid. For one thing, there is less development assistance now available, though the health sector has fared better than other sectors (Michaud and Murray, 1994).

There is a greater demand and opportunity to link aid to the soundness of recipient country's policies and their efforts at implementation, rather than other political or non-sectoral strategic goals. Governments and health agencies have become increasingly frustrated by fragmented approaches to health strategies and foreign aid. The common constraints of poor capacity utilization and weak health systems have also pointed to the need to try different approaches. In the international health community, many detect a sense of urgency that there may be few remaining opportunities to revitalize development assistance in health (Ibid). The international health community has promoted a long series of initiatives with varying success. It is hard to maintain momentum by simply replacing one technical initiative with another, even though development institutions periodically need to do this to redefine themselves and what they offer (Foster, 1987). The SWAp is a more fundamental change in the way organizations behave and relate to each other than was the case with previous initiatives. Current popular management culture has also played a role by encouraging greater networking and innovation, making it easier for bureaucracies to join the new types of partnerships found in SWAps.

Cassels (1997) describes the SWAp as a convergence of two different development perspectives, non-project aid with its macro-economic origins, and sector specific project aid. 
In low-income countries, macro-economic dialogue between governments and donors has become increasingly focused on issues of management and distribution of public resources, and on the role of the State in providing basic public services, including health. Financial support for macro-economic dialogue has largely been provided through adjustment lending and non-project grant assistance. These financial instruments can take several forms, but usually provide quick disbursing funds through national budgets, and are here collectively labeled as non-project aid. Non-project assistance has been effective in meeting balance of payment needs, but has been less effective in promoting long-term sectoral objectives and in controlling distortions in resource allocation. Non-project aid is typically limited to short-term cycles, and is tightly linked to macro-economic or political considerations, as opposed to how efficient or equitable is a country's health system. It may involve attaching conditions as conditions for providing funds to the health sector. It has been difficult to make funding contingent on implementation of more complex policy reforms, particularly under the constraints of non-project aid (Ibid). Though there are exceptions (usually when the policy change has strong local ownership, is limited in scope, and part of a clear program that can be implemented over a short time-frame), financing based on precedent conditions for policy statements has not been an effective way to sustain implementation of longer-term reform programs (Peters and Shiyan, 1998).

Project aid is the most common form of assistance in the health sector, and has left a mixed legacy (Walt et al., 1999). In many cases, well-designed projects have created significant changes in how health interventions are provided, yielding healthy behaviours and saving lives. Projects have been less effective in supporting meaningful policy dialogue and reform, and particularly to improve overall resource planning and allocation (Addai, 2001). Problems arise when countries become excessively reliant on project approaches. When there are many projects in a country, it has made it difficult for governments to develop and implement coherent sectoral policies, resulting in greater fragmentation, duplication of efforts, and conflicts in approaches and priorities between government and donor-funded efforts. They also strain government systems. Governments not only have to deal with many donor missions and reporting requirements, but must staff multiple project implementation units and operate many parallel project administrative systems. Prior to undertaking SWAps, the Ministry of Health in Mozambique had over 120 projects and Sierra Leone's had 47 project units, in both cases outstripping their administrative capacity. In Bangladesh, the last donor consortium divided their assistance among 66 project management units, though the number swelled to over 100 (Peters and Shiyan, 1998). The typical problem with parallel systems is that they undermine capacity in the Ministry of Health, and distract senior staff who would otherwise be fulfilling strategic responsibilities. Projects and project units also create their own special interests, which can undermine sectoral objectives. Many projects have relatively inflexible and over-specified designs, often because of requirements for agency approvals (Cassels, 1997). Such designs either render projects less relevant to changing circumstances, or require significant costs when changes are pursued. Since most donors conceive of projects as providing investment rather than recurrent expenditures, a dominant role of such projects can exacerbate budgetary imbalances, particularly between capital and non-wage recurrent 
expenditures. It is not uncommon that projects originate from donor concerns, rely on preparation through external consultants, and do not have the necessary government ownership to successfully implement the project after it has been approved. From the perspective of donor agencies, the problems that can result from these types of traditional project approaches include long preparation times, high administrative costs, implementation delays, local managerial passivity and subterfuge, and ultimately limited sustainability and impact (Ibid).

\section{Zimbabwe's Policy Response}

The health policy is currently being implemented in partnership with the World Health Organization (WHO), through the Country Cooperation Strategy 2008-2013, to fulfil regional and international plans, policies, programmes and projects. Amongst these include the Millennium Development Goals (MDGs), and the Ouagadougou Declaration on Primary Health Care and Health Systems in Africa (Government of Zimbabwe, 2009; World Health Organization, 2008). It is also being implemented in line with other international, continental and regional health protocols which include the African Union (AU) Health Plan, the East, Central and Southern Africa (ECSA) Health Community Agreements, and the Southern African Development Community (SADC) Health Sector Protocol. It is also being implemented in line with the WHO global priorities, the WHO Medium-Term Strategic Plan (MTSP), the WHO African Region orientations, the Zimbabwe United Nations Development Assistance Framework (ZUNDAF 2007-2011). It takes into consideration the importance of national development strategies as defined in the Zimbabwe Economic Development Strategy (ZEDS 2009-2013). The policy is implemented through the current National Health Strategy (2009-2013), Equity and Quality in Health, A People's Right. This instrument is a successor to the National Health Strategy (1997-2007), Working for Quality and Equity in Health, Economic Structural Adjustment Programme of 1992 and the Plan for Equity in Health of 1980 (Ibid).

\subsection{Institutional framework}

Health care services in Zimbabwe are provided by the Public Sector, Private Medical Sector and the Not for Profit Sector. In the Public Sector, the Ministry of Health and Child Welfare (MoHCW), and Local Authorities, which consist of Rural and Urban District Councils, are the major providers of health services in Zimbabwe. Other providers in this category include the Defence Forces, the Prison Services, the Police, and the Ministry of Education Sports and Culture. The Private for Profit Medical Sector consists of Private Clinics, Traditional Health Practitioners, Private Hospitals and General Practitioners. The Not For Profit Private Sector includes Medical Missions and Non Governmental Organization (Government of Zimbabwe, 2009). Through these providers, the National Health Strategy is being implemented, monitored and evaluated in the context of the regular Ministry of Health and Child Welfare activities. 


\subsubsection{Role of the Ministry of Health}

By facilitating the formulation of the National Health Strategy, the head office of the Ministry has assumed its strategic role of setting policy and guidelines based on the information generated by the operational level. The Secretary for Health and Child Welfare also appoints a Committee to oversee the implementation, monitoring and evaluation of the five year health sector plan. The Secretariat of this Committee is the Policy, Planning Monitoring and Evaluation Division (PPMED) whose main role is to monitor concrete achievements through annual assessment of plans, programmes and projects (Ibid). This is done in partnership with the National Planning Forum, which consists of other providers in the private and voluntary sectors. Within the context of the National Health Strategy, the PPMED plays a role of devising and designing clear mechanisms for accountability, coordinates the planning, monitoring and evaluation process of all health activities proposed in this strategy. It also co-ordinates capacity building in planning, monitoring and evaluation, formulates and applies monitoring instruments and ensure timely submission of reports on reviews. At the provincial level, the Provincial Medical Director's office is the local representative of the Ministry of Health and Child Welfare and is therefore accountable to the Ministry and Government in ensuring that health services in the province are delivered in accordance with the national health priorities (Government of Zimbabwe, 2009; World Health Organization, 2008).

The Provincial level has to make sure that all stakeholders in a province are fully aware of the National Health Strategy and their roles in making it a success. Whilst all plans must comply with the National Health Strategy guidelines, the provincial office has to ensure that specific area peculiar concerns receive due attention and resources (Government of Zimbabwe, 2009). At Central, Provincial and District hospitals, practical implementation of the 5 Year Plan is organised and managed. Once the resource envelope is known, the operational level is expected to prepare a detailed implementation programme. The communities are also expected to make a contribution through health centre committees or community health councils to identify health needs, set community priorities, mobilize and manage local resources for health.

\subsubsection{Stakeholders in health}

Inclusive participation by all stakeholders for successful implementation is being prioritised in the current National Health Strategy. Amongst the stakeholders include the community, Health Services Board, Urban Local Authorities and Mission Hospitals. The stakeholders also include the Civil Society, made up of local and international Non-Governmental Organizations, the business sector and Private Medical Services (Ibid). Training Institutions, Bilateral and multilateral donors, the United Nations Family, regulatory bodies and other government sectors also constitute stakeholders. They are included in the implementation, evaluation and monitoring committee, earlier mentioned.

All stakeholders are responsible for familiarizing themselves with the National Health Strategy and ensuring that their plans, activities and results are aligned, communicated and 
contributed towards the nationally identified priorities outlined in the strategy. Their main role is to use this plan to work in partnership with the Ministry of Health in identifying deficient gaps so as to provide support, to address unfulfilled implementation areas of the strategy. Key issues around inclusive implementation arrangements considered in the current National Health Strategy are thus aimed at informing and mobilizing all stakeholders in the health sector around the National Health Strategy. The need to foster, encourage and facilitate meaningful community participation in the health sector, strengthen mechanisms for partnership, collaboration and funding of health sector activities to implement the wide National Health Strategy are also part of the inclusive implementation arrangement (World Health Organization, 2008).

\subsection{Context and Development Assistance in the SWAp}

Zimbabwe has, in the past eight years, gone through severe economic recession, floods and cyclones and droughts which have led to severe food deficits (Government of Zimbabwe, 2009; World Health Organization, 2008). These factors, compounded by high rates of HIV infection and repeated cholera and other outbreaks, have caused a humanitarian crisis in the country. Political differences with major donor nations have resulted in changes in approach by many donors who now direct their assistance to humanitarian needs such as food, shelter and epidemic response at the expense of health development needs. These funds are now increasingly being channelled through either NGOs or the UN agencies rather than given directly to government (World Health Organization, 2008).

\subsection{Main Development Partners in Zimbabwe's Health Sector}

The main development partners in Zimbabwe's health sector are a cross section of both multilateral and bilateral institutions, international NGOs, and humanitarian and faith-based organizations (Government of Zimbabwe, 2009; World Health Organization, 2008). They include the European Union (EU), United States Agency for International Development (USAID), the Center for Disease Control (CDC) and the UK's Department for International Development (DFID). The United Nations agencies working in health are the United Nations Population Fund (UNFPA), United Nations Children's Fund (UNICEF), United Nations AIDS (UNAIDS) and United Nations Development Programme (UNDP). Other mechanisms through which Zimbabwe is receiving funding include the Global Fund to Fight AIDS, Tuberculosis and Malaria (GFATM), the Expanded Support Programme (ESP), the consolidated appeal process (CAP), Global Alliance for Vaccines and Immunization (GAVI) and the Health Metrics Network (World Health Organization, 2008).

\subsection{Other Funding Mechanisms}

The Global Alliance for Vaccines and Immunization (GAVI) has provided support from 2002 in immunization services strengthening, injection safety, vaccine support and technical support to EPI during the formulation of the financial sustainability plan and the costed EPI multi-year plan. Further support in EPI has been received from Helen Keller International and 


\section{Ml Macrothink}

Rotary International. The Health Metrics Network (HMN) has given support for strengthening various aspects of the national health information system. The MoHCW has also been engaging non-traditional donors for support in recent years. This has been done through government-to-government agreements. The South Koreans, Russians, Iranians, Chinese, Egyptians and Cubans have provided support in various areas of health care delivery that include malaria control, traditional medicine and curative services (Ibid). The following table outlines the main areas of development assistance and partnerships as of 2011.

Table 1: Main areas of Development Assistance and Partnerships

\begin{tabular}{|c|c|c|c|c|}
\hline $\begin{array}{l}\text { Partner or } \\
\text { funding } \\
\text { mechanism }\end{array}$ & $\begin{array}{l}\text { Type of } \\
\text { Partnership }\end{array}$ & Principal Area of Intervention & $\begin{array}{l}\text { Funding } \\
\text { (millions) }\end{array}$ & Period \\
\hline The EU & Bilateral & $\begin{array}{l}\text { Health Systems Strengthening, } \\
\text { HIV/AIDS, Reproductive health, } \\
\text { malaria control, water and } \\
\text { sanitation, }\end{array}$ & Euro 150 & 2005-2007 \\
\hline USAID & Bilateral & HIV/AIDS and Family planning, & $\begin{array}{l}\text { USD } \\
176.9\end{array}$ & $2000-2007$ \\
\hline $\mathrm{CDC}$ & Bilateral & HIV/AIDS and Tuberculosis, & USD 50 & 2001-2008 \\
\hline DFID & Bilateral & $\begin{array}{l}\text { HIV/AIDS, maternal health, malaria } \\
\text { control, immunization, emergency } \\
\text { and vital medicines support, }\end{array}$ & $£ 45$ & $2007-2008$ \\
\hline UNFPA & Multilateral & $\begin{array}{l}\text { Reproductive health, population and } \\
\text { development, } \\
\text { mainstreaming, }\end{array}$ & USD 40.5 & 2007-2011 \\
\hline UNICEF & Multilateral & $\begin{array}{l}\text { Young child survival and } \\
\text { development, water, sanitation and } \\
\text { hygiene, HIV/AIDS, }\end{array}$ & USD 91 & 2007-2011 \\
\hline UNAIDS & Multilateral & HIV/AIDS, & USD 58 & 2006 \\
\hline $\begin{array}{l}\text { The Global } \\
\text { Fund }\end{array}$ & & $\begin{array}{l}\text { HIV/AIDS, Tuberculosis and } \\
\text { Malaria, }\end{array}$ & USD 125 & 2004-2007 \\
\hline The ESP & & HIV/AIDS, & USD 36 & $2007-2008$ \\
\hline CAP & & $\begin{array}{l}\text { Cholera, ARVs, Emergency } \\
\text { Preparedness and Response. }\end{array}$ & USD 1,5 & $2006-2008$ \\
\hline
\end{tabular}

(WHO Regional Office for Africa: 2009, p12) 


\subsection{Coordination of Development Assistance}

Government, through its economic development strategies and partnership with the UN family through the Zimbabwe UN Development Assistance Framework (ZUNDAF), provides partners with information on the national development agenda (World Health Organization, 2008). Through its strategic and yearly plans, the MoHCW in turn provides its partners with guidance on the areas of development assistance. There is a Donor Section in the MoHCW that coordinates all donor funds that are channelled through the ministry. A number of mechanisms have been put in place to allow for receiving, disbursing, tracking and reporting on the use of donor assistance.

The Global Fund resources are managed by the Country Coordinating Mechanism (CCM) while the Expanded Support Programme (ESP) Working Group coordinates ESP funding. ZUNDAF provides a forum for coordination of government and UN activities in Zimbabwe Working groups and clusters have also been established. Through the Resident Coordinator with technical advice from the Office for the Coordination of Humanitarian Affairs (OCHA) all humanitarian activities are coordinated. The Interagency Humanitarian Coordination Mechanism has been constituted as well as the Donors group. In the context of improving coordination among the different sector partners, the Cluster Approach has been recently adopted and WHO is leading the Health Cluster (Government of Zimbabwe, 2009; World Health Organization, 2008). Under the World Bank, the Multi-donor Trust Fund (MDTF) is being created, with health as a component of the Basic Services group. The Health Development Partners Coordination Group (HDPCG) was formed in 2007 in recognition of the need for better information sharing and coordination of efforts among donors and development partners in the health sector. The HDPCG aims to adopt a coordinated approach and, possibly, joint actions in areas such as essential drugs supply and support to human resources in health. The group is currently chaired by the EU with WHO holding the deputy position (Ibid).

\section{Conclusions}

The discourse concluded that a Sector Wide Approach (SWAp) is a sustained government-led partnership with donor agencies and the civil society in-which sector-wide interventions are applied to an expenditure framework and national implementation system for the health policy. This approach enables the government to undertake explicit health sector reforms to meet sectoral and national development objectives. Within this approach, capacity in the health sector is built around four key areas which include country leadership and ownership, institutional and management capacity, flow of resources, and monitoring and evaluation. The main elements of the SWAp include the policy framework, institutional framework and expenditure framework for effective and efficient implementation. The rationale is to systematically build the capacity of health delivery systems and structures, for the realization health policy objectives through effective and efficient utilization of collaboratively mobilized resources for the realization of sustainable development in health. It was concluded that Zimbabwe has responded to the Sector Wide Approach (SWAp) by adopting the World 
Health Organization (WHO)'s Country Cooperation Strategy 2008-2013, being implemented through the National Health Strategy (2009-2013), Equity and Quality in Health, A People's Right.

Within this framework, health services are provided by the Public Sector, Private for Profit Sector and the Private Not for Profit Sector. Within the Public Sector, it was concluded that the Ministry of Health and Child Welfare (MoHCW), and Local Authorities, which consist of Rural and Urban District Councils, are the major providers of health services in Zimbabwe. Other providers in this category include the Defence Forces, the Prison Services, the Police, and the Ministry of Education Sports and Culture. The Private for Profit Medical Sector consists of Private Clinics, Traditional Health Practitioners, Private Hospitals and General Practitioners. The Private Not for Profit Sector, also known as the Voluntary Sector, consists of Medical Missions and Non Governmental Organizations. It was also concluded that Zimbabwe's development partners in health are drawn from this sector, which consists of a cross section of both multilateral and bilateral institutions, international NGOs, and humanitarian and faith-based organizations.

Amongst these include the European Union (EU), United States Agency for International Development (USAID), the Center for Disease Control (CDC) and the UK's Department for International Development (DFID). The United Nations agencies working in health are UNFPA, UNICEF, UNAIDS and UNDP. The discussion also concluded that Zimbabwe is receiving funding through the Global Fund to Fight AIDS, Tuberculosis and Malaria (GFATM), the Expanded Support Programme (ESP), the consolidated appeal process (CAP), Global Alliance for Vaccines and Immunization (GAVI) and the Health Metrics Network. Other funding mechanisms are drawn from the Global Alliance for Vaccines and Immunization (GAVI), Helen Keller International and Rotary International. It was also concluded that the MoHCW has also been engaging non-traditional donors for support in recent years through government-to-government agreements. Amongst these include the South Koreans, Russians, Iranians, Chinese, Egyptians and Cubans who have provided support in various areas of health care delivery.

Coordination of development assistance is achieved through the government, its economic development strategies and partnership with the UN family through the Zimbabwe UN Development Assistance Framework (ZUNDAF), which provides partners with information on the national development agenda. Through its strategic and yearly plans, the MoHCW in turn provides its partners with guidance on the areas of development assistance. There is a Donor Section in the MoHCW that coordinates all donor funds that are channelled through the ministry. The Global Fund resources are managed by the Country Coordinating Mechanism (CCM) while the Expanded Support Programme (ESP) Working Group coordinates ESP funding. ZUNDAF provides a forum for coordination of government and UN activities in Zimbabwe Working groups and clusters have also been established. Through the Resident Coordinator with technical advice from the Office for the Coordination of Humanitarian Affairs (OCHA) all humanitarian activities are coordinated. 


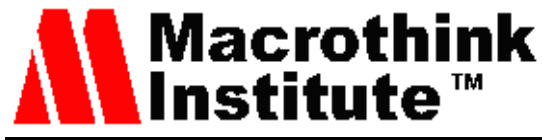

The Interagency Humanitarian Coordination Mechanism has been constituted as well as the Donors group. In the context of improving coordination among the different sector partners, the Cluster Approach has been recently adopted and WHO is leading the Health Cluster. Under the World Bank, the Multi-donor Trust Fund (MDTF) is being created, with health as a component of the Basic Services group. The Health Development Partners Coordination Group (HDPCG) was formed in 2007 in recognition of the need for better information sharing and coordination of efforts among donors and development partners in the health sector. The HDPCG aims to adopt a coordinated approach and, possibly, joint actions in areas such as essential drugs supply and support to human resources in health.

It was concluded that the Ministry of Health has, by playing a strategic role in the formulation of the National Health Strategy, played a leading role in the SWAp. The Secretary for Health and Child Welfare through the Policy, Planning Monitoring and Evaluation Division (PPMED) Committee monitors the implementation process. This is done in partnership with the National Planning Forum, which consists of other providers in the private and voluntary sectors. Within the context of the National Health Strategy, the PPMED plays a role of devising and designing clear mechanisms for accountability, coordinates the planning, monitoring and evaluation process of all health activities proposed in this strategy. It also co-ordinates capacity building in planning, monitoring and evaluation, formulates and applies monitoring instruments and ensure timely submission of reports on reviews. At the provincial level, the Provincial Medical Director's office is the local representative of the Ministry of Health and Child Welfare and is therefore accountable to the Ministry and Government in ensuring that health services in the province are delivered in accordance with the national health priorities. The discussion concluded that practical implementation of the five year plan is organized and managed at the Central, Provincial and District hospitals.

Inclusive participation by all stakeholders for successful implementation is being prioritised in the current National Health Strategy. Amongst the stakeholders listed in the National Health Strategy include the community, Health Services Board, Urban Local Authorities and Mission Hospitals. The stakeholders also include the Civil Society, made up of local and international Non-Governmental Organizations, the business sector and Private Medical Services. Training Institutions, Bilateral and multilateral donors, the United Nations Family, regulatory bodies and other government sectors also constitute stakeholders. They are part of the implementation, monitoring and evaluation committee mentioned earlier. In all, the SWAp is expected to contribute towards effectiveness, efficiency, responsiveness, accountability and sustainability in the implementation of the global health policy. 


\section{Acknowledgement}

I wish to thank God for everything and express my appreciation to Doctor Gideon Zhou and Professor John Makumbe, Department of Political and Administrative Studies, University of Zimbabwe.

\section{References}

Addai, E. (2001) Capacity Building and Systems Development for SWAps; The Experience of the Ghana Health Sector. (Prepared for the DFID Health Systems Resource Centre) http://www.sti.ch/pdfs/swap154.pdf (Accessed 17/3/2012)

Brown, A. (2000) Current Issues in Sector-Wide Approaches for Health Development: Uganda Case Study. http://whqlibdoc.who.int/hq/2000/WHO_GPE_00.3.pdf (Accessed $17 / 3 / 2012)$

Brown, A. (2002) Current Issues in Sector Wide Approaches for Health Development: Mozambique Case Study. http://whqlibdoc.who.int/hq/2000/WHO_GPE_00.4.pdf (Accessed $17 / 3 / 2012)$

Cassels, A. (1997) A Guide to Sector-Wide Approaches for Health Development: Concepts, Issues and Working Arrangements. World Health Organization, Geneva

Conway, T. (2000) Current Issues in Sector Wide Approaches for Health Development: Cambodia Case Study. http://whqlibdoc.who.int/hq/2000/WHO_GPE_00.2.pdf (Accessed $17 / 3 / 2012)$

Dollar, D. Pritchett, L. (1998): Assessing Aid; What Works, What Doesn't, and Why. Oxford University Press, Oxford

Foster, G et al. (2000): Sector Wide Approaches for Health Development. A Review of Experience. WHO, Geneva

(WHO/GPE/00.1) www.who.int/countryfocus/resources/guide_to_who_in_swap_en.pdf (Accessed 17/3/2012)

Gilson, L. Adusei, J. Arhin, D. Hongoro, C. Mujinja, P. Sagoe, K. (1997) Should African governments contract out clinical health services to church providers?. In Bennet, S. McPake, B. Mills, A. J. (eds) (1997) Private health providers in developing countries: serving the public interest?. London: Zed Books: p276-302

Government of Zimbabwe, (2009) National Health Strategy, 2009-2013: Equity and Quality in Health-A People's Right. Ministry of Health and Child Welfare, Harare

Michaud, C., Murray, C. L. J. (1994) External assistance to the health sector. In Munishi, G. K. (2003): Intervening to address constraints through health sector reforms in Tanzania; some gains and the unfinished business. Journal of International Development 15, 3, 
p115-131

Peters, D. and Shiyan, C. (1998) The Sector Wide Approach in Health; What is it? Where is it Leading? International Journal of Health Planning and Management. 1998-13, p177-190

Saltman, R. B. (1994) A Conceptual Overview of Recent Health Care Reforms. European Journal of Public Health, 4, p287-293

Travis, P. Bennet, S. Haines, A. Pang, T. Bhutta, Z. Hyder, A. Pielemeier, N. Mills, A. Evans, T. (2004) Overcoming Health System Constraints to achieve Millennium Development Goals: The Lancet, Volume 364, Issue 9437, p900-906

Walt, G. Parignani, E. Gilson, L. Buse, K. (1999) Health Sector Development; from aid coordination to resource management: Journal of Health Policy and Planning, 14, 3, p207-218

WHO, (2008) WHO Country Cooperation Strategy 2008-2013, Zimbabwe: Regional Office for Africa, Brazaville

WHO/UNICEF, (1978) Declaration of Alma-Ata. International Conference on Primary Health Care, Alma-Ata, 6-12 September 1978, Russia

\section{Copyright Disclaimer}

Copyright reserved by the author(s).

This article is an open-access article to be distributed under the terms and conditions of the Creative Commons Attribution license (http://creativecommons.org/licenses/by/3.0/). 